Article

\title{
Identification of Iron Oxide Species in the Framework of Zeolite-Y by Using EDTA Dissolution and Electron Spin Resonance (ESR) Methods
}

Yateman ARRYANTO and Arif RAHMAN

Inorganic Materials Research Group, Department of Chemistry, Faculty of Mathematics and Natural Sciences, Gadjah Mada University, PO BOX Bls 21, Sekip Utara, Yogyakarta 55281, Indonesia

(Manuscript submitted February 15, 2003; accepted May 1, 2003)

\begin{abstract}
Identification of iron oxide species on the framework of zeolite-Y by using EDTA dissolution method and Electron Spin Resonance (ESR) method has been studied. Encapsulation of iron ions in the framework of zeolite was carried out by ion exchange method using ultrasonic cleaner and then followed by dissolution using EDTA solution. The iron oxide was determined by using chemical analysis and Electron Spin Resonance (ESR). From the ESR spectra it was found that encapsulation of iron oxide to the framework of zeolite-Y tends to form two type of iron oxide species, the first type is as $\mathrm{Fe}_{2} \mathrm{O}_{3}$ or $\mathrm{FeOOH}$ (iron oxo species) that are located at site $\mathrm{SI}$ on the inner surface of sodalite and the second type as polycationic species that is located at site SII on the outer surface of sodalite.
\end{abstract}

\section{Introduction}

Iron oxide semiconductor nanoparticles have been attracted much attention to many scientists because of their special magnetic and optoelectronic properties coming out from the particles. The iron oxide nanoparticles have potential application for fuel autoxidation catalyst.[1] for information storage[2] and for color imaging.[3] Many methods of preparing the nanoparticles had been carried out in clays[4] and zeolites.[5] The important matter in preparing nanoparticles is to give a uniform size to the particles and to understand the distribution of iron oxide species on the matrix material, which is important to the magnetic and optoelectronic properties of the material. In order to have the nanoparticles with uniform size and to understand the distribution of metal species on the framework of zeolite, in this paper the distribution of iron oxide species on the framework of zeolite material have been studied by EDTA dissolution method. The iron oxide nanoparticles in zeolite have been encapsulated by ion exchange process using ultrasonic cleaner. The amount of the iron oxide in each sites of the framework of zeolite was examined by dissolution method and characterized by chemical analysis and Electron spin resonance (ESR).

\section{Experimental Methods}

\subsection{Materials and preparation methods}

Zeolite-Y having $\mathrm{SiO}_{2} / \mathrm{Al}_{2} \mathrm{O}_{3}$ mol ratio 5.1 from Zeolyst International was used as a support material. Hydrated ferrous sulfate $\left(\mathrm{FeSO}_{4} 7 \mathrm{H}_{2} \mathrm{O}\right.$ ), EDTA-disodium and Borax (E.Merck) were analytical grade. To $300 \mathrm{~cm}^{3}$ of a borax buffer solution $(\mathrm{pH}=7)$ were added $4 \mathrm{~g}$ of zeolite and iron sulfate aqueous solution in various concentration, and then put it on ultrasonic cleaner under bath system. Sonication was carried for $6 \mathrm{~h}$ at $273 \mathrm{~K}$ under deoxygenated system by bubbling with nitrogen gas. 


\subsection{Analyses and Characterization}

Iron concentration were measured using a Perkin-Elmer 3110 Absorption Spectrophotometer at $\lambda=248.3$ $\mathrm{nm}$. ESR spectra were recorded on the ESR Jeol type JES-REX2X integrated with microwave source X band ESSCXA No. ER 120008-12. Operational condition of ESR in scan range of $5 \times 100 \mathrm{mT}$, time constant of $0.03 \mathrm{~s}$, Modulation Amplitude at $2 \times 1 \mathrm{mT}$, Field set $300 \mathrm{mT}$, Scan time is $120 \mathrm{~s}$, Modulation frequency at $100 \mathrm{kHz}$, temperature $298 \mathrm{~K}$. Microwave frequency $9.47 \mathrm{GHz}$.

\section{Results and Discussion}

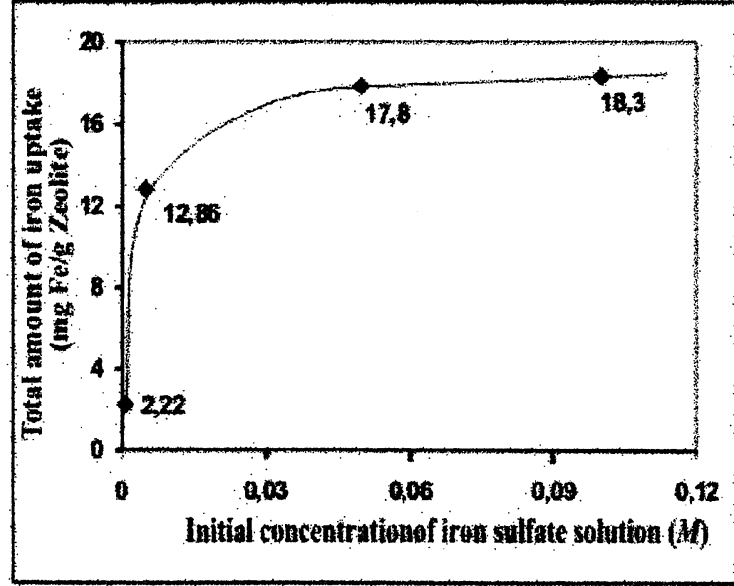

Fig. 1 The influence of various initial concentration of iron sulfate solution on the amount of iron uptake by Zeolite-Y

The influence of various initial concentration of iron sulfate solution to the type on the amount of iron uptake and the type of iron oxide formed were studied at concentration of $0.0005,0.005,0.05$ and $0.1 \mathrm{M}\left(\mathrm{M}=\mathrm{mol} \mathrm{dm}^{-3}\right)$ at $\mathrm{pH} 7$ (oxalate buffer). The relationship between the amounts of iron oxide uptake by the framework of zeolite-Y to the concentration of initial iron sulfate solution is presented in Fig. 1. It can be seen from Fig. 1 that the increase in the initial concentration of iron sulfate increases the amounts of iron uptake and the iron uptake reaches saturation at higher concentration. The relationship is similar to the Langmuir isotherm curve,[6] indicating that the ion exchange process of iron species to the framework of zeolite-Y is high selective to the iron species replacing the sodium ion.

Electron Spin Resonance Spectra, The state of the iron oxide species formed on/in the zeolite-Y structure has been investigated for various initial concentration of iron sulfate solution, the results are presented as Fig. 2a and Fig. 2b. The ESR spectra of iron species were obtained after heating at $373 \mathrm{~K}$ for $12 \mathrm{~h}$ (Fig. 2a) and calcinated at 773 $\mathrm{K}$ for $8 \mathrm{~h}$ (Fig. 2b). It can be seen from Fig.2a that the spectra have two types of asymmetric curves with $g$ factor value of 4.2 and 2 . The $g$ factor of 4.2 is attributed to the iron oxide species encapsulated at hinder area, to be located at site SI the center of double six ring (D6R) of the zeolite-Y framework. The $g$ factor of 2 is attributed to the iron oxide species located at free spin mobility area to be located at site SII (outer surface).[7] Site II is the exchange site located at the surface of sodalite cage that is easier to interact with iron species from iron sulfate solution than site SI that is located in the center of double six ring (D6R).

The intensity of absorption peak of ESR spectra of iron oxide at a $g$ factor of 4.2 is increase with increasing of initial concentration of iron sulfate solution, due to the increase of iron oxide population at site SI. The intensity of the $g$ factor of 2 is increase with increasing initial concentration of iron but at concentration of $0.1 \mathrm{M}$ the intensity is decrease, due to more of free ion $\mathrm{Fe}$ (II) exist in the surface of zeolite. In the calcination process the free iron (II) is transformed into iron oxide. So that the iron oxide in the site II tends to increase the intensity of $g$ factor of 2 , as seen at Fig. 2b. In order to prove that statement, it has been compared $\Delta H_{p p}$ (the difference between magnetic field strength at particular peaks and troughs) of $g$ factor of 2.0 and 4.2 before and after calcination as seen at table 1 . The $\Delta H_{p p}$ of $g$ factor of 2 is attributed to the species of $\mathrm{Fe}\left(\mathrm{H}_{2} \mathrm{O}\right)_{6}{ }^{3+}$.[8,9] The value of $\Delta H_{p p}$ become smaller after calcinations at $773 \mathrm{~K}$ for $8 \mathrm{~h}$ due to water lost from species hydrate iron during calcinations. It can be seen from table 1 that $\left(\Delta H_{p \mathrm{p}}\right)$ of $g$ factor of 2 of sample after calcination is increase by increasing of initial concentration of iron sulfate solution, where as these phenomena are not seen at sample before calcination. 


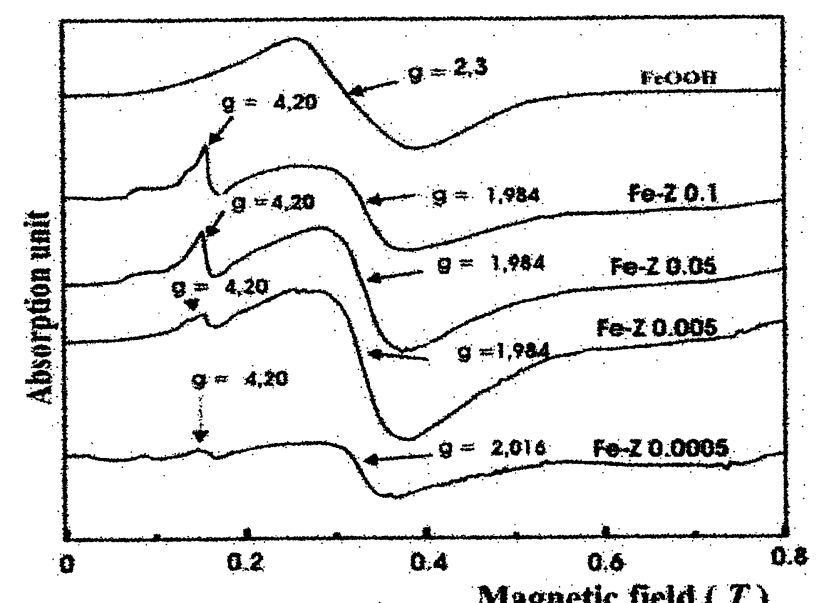

(a)

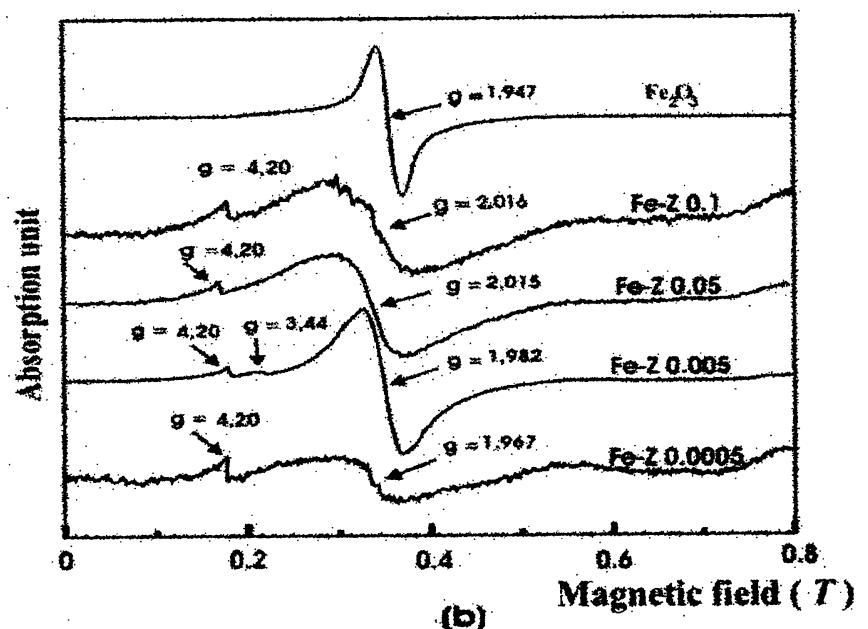

(b)

Fig. 2 ESR Spectra of iron oxide sample prepared for various initial concentration of iron sulfate with heat treatment at (a) $373 \mathrm{~K}$ for $12 \mathrm{~h}$ and (b) $773 \mathrm{~K}$ for $8 \mathrm{~h}$, the spectra was collected at $298 \mathrm{~K}$ by using microwave of $\mathrm{X}$ band

Table .1 $\Delta \mathrm{H}_{\mathrm{pp}}$ value before at after heating at 373 and $773 \mathrm{~K}$

\begin{tabular}{|c|c|c|c|c|c|c|c|}
\hline $\begin{array}{l}\text { Sample } \\
\text { code }\end{array}$ & $\mathbf{g}_{\mathbf{b}}$ & $\begin{array}{c}\Delta \mathbf{H}_{\mathrm{ppb}} \\
(T)\end{array}$ & $\mathbf{g a}_{\mathbf{a}}$ & $\begin{array}{c}\Delta \mathbf{H}_{\mathrm{ppa}} \\
(T) \\
\end{array}$ & $\begin{array}{c}\text { Sample } \\
\text { code }\end{array}$ & g & $\begin{array}{c}\Delta \mathbf{H}_{\mathrm{pp}} \\
(T)\end{array}$ \\
\hline \multirow[t]{2}{*}{ Fe-Z 0.1} & 4.200 & (A) & 4.200 & (A) & Bulk & 1.947 & 0.29729 \\
\hline & 1.984 & 0.11411 & 2.016 & 0.09847 & $\mathrm{FeOOH}$ & 2.300 & 0.12786 \\
\hline \multirow[t]{2}{*}{$\mathrm{Fe}-\mathrm{Z} 0.05$} & 4.200 & (A) & 4.200 & (A) & \multirow{5}{*}{\multicolumn{3}{|c|}{$\begin{array}{l}(\mathrm{A})=\text { Anisotropic } \\
\mathrm{g}_{\mathrm{b}}=\mathrm{g} \text { sample heating at } 373 \mathrm{~K} \\
\mathrm{~g}_{\mathrm{a}}=\mathrm{g} \text { sample heating at } 773 \mathrm{~K} \\
\Delta \mathrm{H}_{\mathrm{ppb}}=\Delta \mathrm{H}_{\mathrm{pp}} \text { sample heating at } 373 \mathrm{~K} \\
\Delta \mathrm{H}_{\mathrm{ppa}}=\Delta \mathrm{H}_{\mathrm{pp}} \text { sample heating at } 773 \mathrm{~K}\end{array}$}} \\
\hline & 1.984 & 0.08424 & 2.015 & 0.07618 & & & \\
\hline \multirow[t]{3}{*}{$\mathrm{Fe}-\mathrm{Z} 0.005$} & 4.200 & (A) & 4.200 & (A) & & & \\
\hline & 1.984 & 0.11419 & 1.982 & 0.04615 & & & \\
\hline & 5 & - & $\begin{array}{l}3.440 \\
4.200\end{array}$ & (A) & & & \\
\hline $\mathrm{Fe}-\mathrm{Z} 0.0005$ & 2.016 & 0.08709 & 1.967 & 0.06017 & & & \\
\hline
\end{tabular}

From table 1 it can also be seen that after calcinations at $773 \mathrm{~K}$ for $8 \mathrm{~h}$, the $g$ factor slightly increases to 2.016 for samples prepared at initial concentrations of iron sulfate solution at 0.1 and $0.05 \mathrm{M}$. The shift of $g$ factor into the larger value is attributed to the removal of iron oxide from site SII to site SII' on sodalite cage.[5,10] A similar shift is not observed to iron oxide species of the $g$ factor of 4.2 that has more stable than the iron oxide species of the $g$ factor of 2 obtained by calcinations at $773 \mathrm{~K}$ for $8 \mathrm{~h}$. From the ESR spectra it is observed that encapsulation of iron oxide to the framework of zeolite-Y tends to form two type of iron oxide species, the first type is the $\mathrm{Fe}_{2} \mathrm{O}_{3}$ or $\mathrm{FeOOH}$ (iron oxo species) that is located on the inner surface of sodalite and the second type is the polycationic species that is located at site SII on the outer surface of sodalite.

Dissolution process by EDTA solution In order to prove the primary finding on iron species on the frame work of Zeolite-Y as mentioned above, the dissolution of iron oxide species has been carried out by using EDTA solutions at $\mathrm{pH} 7$ and then the resulting samples were charaterized by using ESR spectroscopy, the quantitative data is presented at table 2 and qualitative data of ESR is presented at Fig. 3.

Table.2 Precentage of the amount of iron dissolved by using EDTA solution and water

\begin{tabular}{lcc}
\hline Sample code & $\begin{array}{c}\text { \% Amount of iron dissolute } \\
\text { by using EDTA }\end{array}$ & $\begin{array}{c}\text { \% Amount iron dissolute } \\
\text { by using aqueous }\end{array}$ \\
\hline Fe-Z 0.005 & 25.04 & 32.81 \\
Fe-Z 0.05 & 85.39 & 46.46 \\
Fe-Z 0.1 & 78.25 & 46.34 \\
\hline
\end{tabular}


Table 2 shows that the amount of iron dissolved by EDTA solutions are almost twice than iron dissolved by water, probably because of a stronger coordination of EDTA with its six coordination sites, which are two amines and four carboxyls to form a violet solution of Fe-EDTA.[11] $\mathrm{H}_{2} \mathrm{O}$ is weak type of ligand to iron oxide so it is not easily to dissolute iron from the framework of zeolite-Y. Dissolution of iron oxides by $\mathrm{H}_{2} \mathrm{O}$ molecules take place due to cathodic corrosion.[12] After dissolution by using EDTA solution, absorption peak of ESR spectra at $g$ factor of 3.44 disappear as seen at Fig. 3. It is attributed to the interaction between EDTA and the weak site of iron oxide species encapsulated at super cage of the framework of zeolite-Y. At site III and III' the iron (III) is stabilized by four oxygen and while at site I or II the iron (III) are stabilized by six of oxygen of the framework of zeolite-Y. So iron oxide at site III is easy to dissolved by EDTA than at site I or II to form complex solution or Fe-EDTA.

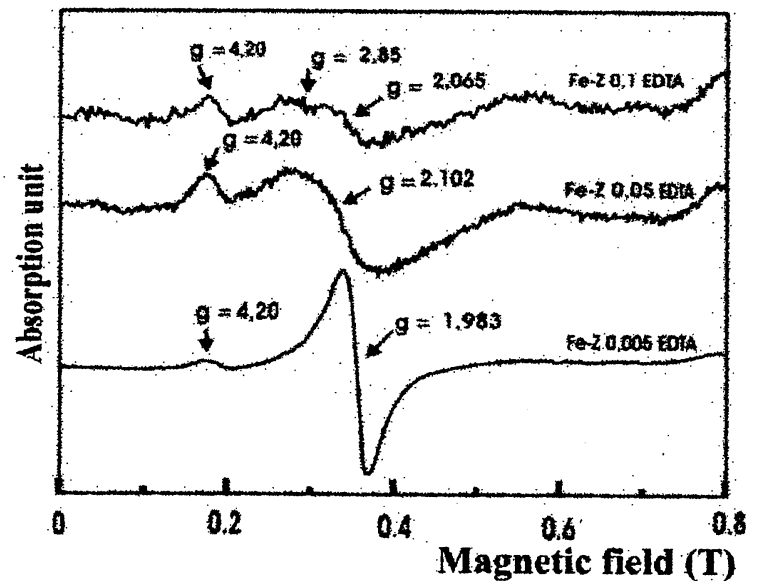

Fig. 3 ESR Spectra of iron oxide after dissolution by EDTA $0.1 M$ and measured at $298 \mathrm{~K}$ by using microwave of $\mathrm{X}$ band.
Table 3. The $g$ factor of sample prepared by various initial concentration of iron sulfate solution before and after dissolution

\begin{tabular}{|c|c|c|c|c|}
\hline Sample & g Fe-Z & $\begin{array}{c}\text { Site } \\
\text { expected }\end{array}$ & $\underset{\text { EDTA }}{g_{F Q-Z}}$ & $\begin{array}{c}\text { Site } \\
\text { expected }\end{array}$ \\
\hline$F \theta-Z 0.1$ & $\begin{array}{c}4.200 \\
2.016 \\
-\end{array}$ & $\begin{array}{l}\text { SI } \\
\text { SII' }\end{array}$ & $\begin{array}{l}4.200 \\
2.065 \\
2.850\end{array}$ & $\begin{array}{l}\text { SI } \\
\text { SII' } \\
\text { SII' }\end{array}$ \\
\hline $\mathrm{Fe}-\mathrm{Z} 0.05$ & $\begin{array}{l}4.200 \\
2.015\end{array}$ & $\begin{array}{l}\text { SI } \\
\text { SIl' }\end{array}$ & $\begin{array}{l}4.200 \\
2.102\end{array}$ & $\begin{array}{l}\text { SI } \\
\text { SII' }\end{array}$ \\
\hline $\mathrm{Fe}-\mathrm{Z} 0.005$ & $\begin{array}{l}4.200 \\
1.982 \\
3.440\end{array}$ & $\begin{array}{l}\text { SI } \\
\text { SII } \\
\text { SIII }\end{array}$ & $\begin{array}{c}4.200 \\
1.983 \\
-\end{array}$ & $\begin{array}{l}\text { SI } \\
\text { SII } \\
.\end{array}$ \\
\hline
\end{tabular}

It can be seen from Fig. 3 that absorption intensity at $g$ factor of 2 decreases significantly, it is almost similar to the intensity of $g$ factor of 4.2. These phenomena prove that dissolution process by EDTA will affect the iron oxide at site III and II' which is closer to the surface of sodalite cage. The $g$ factor intensity of 4.2 at site I was relatively constant because their high stability. Summary of $g$ factor and $\Delta H_{p p}$ of sample iron oxide before and after dissolution by using EDTA solution is presented at table 3 .

\section{References}

1) J. M. Pickard and E. G. Jones, Energy \& Fuels, 11, 1232-1236 (1997).

2) L. Gunther, Phys world, 3, 28, (1990).

3) R. G. L. Andran, and A. P. Huguenards, US Patent, 4, 302, 532. (1981).

4) H. Miyoshi and H. Yoneyama, J.Chem. Soc. Faraday Trans, 85, 1873-1880 (1989).

5) X. S. Zao, G. Q. Lu, and G. J. Millar, J. Porous Material, 3, 61-66 (1996).

6) M. Abe, 1995, "Ion Exchange and Solvent Extraction, A Series of Advance" (Eds. Y. Marcus and J.A. Marinsky) Marcel Dekker, New York (1995), Chap.5, pp 381-440.

7) J. C. Vedrine, "Guidelines for Mastering The Properties of Molecular Sieves" (Eds. D. Barthomeuf, E. G. Derouane and W. Holderich), Plenum Press, New York (1990), pp 121-143.

8) A. K. Sinha, C. V. V. Satyanarayana, D. Srinivas, S. Sivasanker, P. Ratnasamy, Micro and Mesoporous Mat., 35-36, 471-481 (2000).

9) J. Xu, J-S. Yu, S.J. Lee, B. Y. Kim, and L. Kevan, J. Phys. Chem. B. 104, 1307-1314 (2000).

10) A. A. Verbeckmoes, B. M. Weckhusyen, R. M. Schoonheydt, Micro and Mesoporous Mat., 22, 165-178, (1998).

11) M. A. Zaitoun and C. T. Lin, J. Phys. B, 101, 1857-1860 (1997).

12) M. R. Hoffman, S. T. Martin, W. Choi and D. W. Bahnemann, Chem. Rev. 95, 65-96 (1995). 